Case Report

\title{
Acutely Onset Amiodarone-Induced Angioedema in a Patient with New Atrial Fibrillation
}

\author{
Hossein Vakili, ${ }^{1}$ Isa Khaheshi, ${ }^{1}$ Mehdi Memaryan, ${ }^{1}$ Habib Haybar, ${ }^{2}$ and Shooka Esmaeeli ${ }^{3}$ \\ ${ }^{1}$ Cardiovascular Research Center, Modarres Hospital, Shahid Beheshti University of Medical Sciences, Tehran, Iran \\ ${ }^{2}$ Cardiovascular Research Center, Ahvaz Jundishapur University of Medical Sciences, Ahvaz, Iran \\ ${ }^{3}$ Students' Scientific Research Center (SSRC), Tehran University of Medical Sciences, Tehran, Iran \\ Correspondence should be addressed to Isa Khaheshi; isa_khaheshi@yahoo.com
}

Received 26 October 2014; Accepted 3 December 2014; Published 25 December 2014

Academic Editor: Yahia A. Raja’a

Copyright (C) 2014 Hossein Vakili et al. This is an open access article distributed under the Creative Commons Attribution License, which permits unrestricted use, distribution, and reproduction in any medium, provided the original work is properly cited.

\begin{abstract}
A 50-year-old man was admitted to our emergency department due to new episode of palpitation. He had history of angioplasty of right coronary artery (RCA) with drug eluting stent 2 years ago. His electrocardiogram revealed atrial fibrillation (AF). Intravenous amiodarone $150 \mathrm{mg}$ during 10 minutes and then $1 \mathrm{mg} / \mathrm{min}$ infusion were started to achieve rate control and pharmacologic conversion to sinus rhythm. After 60 minutes of starting amiodarone infusion, he developed swelling of the skin around his mouth and eyes, and also mucosa of the mouth, eyes and tongue. To conclude, angioedema should be considered a rare side effect of amiodarone which is used broadly in cardiovascular field.
\end{abstract}

\section{Introduction}

Atrial fibrillation $(\mathrm{AF})$ is the most familiar cardiac arrhythmia in clinical practice $[1,2]$. Amiodarone, a class III long-acting antiarrhythmic drug, has been showed to be superior to other antiarrhythmic medications for the pharmacologic cardioversion of AF and maintenance of sinus rhythm especially in the setting of coronary artery disease and congestive heart failure [3-5].

\section{Case Presentation}

A 50-year-old man was admitted to our emergency department due to new episode of palpitation 3 hours ago. He had history of angioplasty of right coronary artery (RCA) with drug eluting stent 2 years ago. He had no complaint of chest pain, dyspnea, or palpitation until this morning when he woke up with palpitation. His drug history included aspirin $81 \mathrm{mg}$ daily, metoprolol $50 \mathrm{mg}$ daily, atorvastatin $20 \mathrm{mg}$ daily, and isosorbide dinitrate $10 \mathrm{mg}$ BID. On physical examination, blood pressure was $110 / 70$, heart rate was 138 beats $/ \mathrm{min}$, respiratory rate was 14 , and body temperature was $36.9^{\circ} \mathrm{C}$. The remaining of his physical examination was not remarkable.
His electrocardiogram revealed atrial fibrillation (AF) with the rate of about 130 beats/min with no ST segment or T wave changes.

Bed side transthoracic echocardiography demonstrated ejection fraction of $45 \%$, inferior wall mild hypokinesia, mild diastolic dysfunction, and trivial mitral regurgitation.

Due to new atrial fibrillation and stable hemodynamic status, intravenous amiodarone $150 \mathrm{mg}$ during 10 minutes and then $1 \mathrm{mg} / \mathrm{min}$ infusion were started to achieve rate control and pharmacologic conversion to sinus rhythm.

After 60 minutes of starting amiodarone infusion, he developed swelling of the skin around his mouth and eyes and also mucosa of the mouth, eyes, and tongue.

Moreover, he had complained of slight dyspnea; however, his hemodynamic state was stable and pulse oximetry showed 96\% saturation with Oxygen in ambient air; so, tracheal intubation was not required.

Amiodarone infusion was immediately stopped and intravenous hydrocortisone $100 \mathrm{mg}$ and chlorpheniramine $10 \mathrm{mg}$ were introduced.

After 2 hours, his periocular and perioral swellings were made somehow better and he had no dyspnea or stridor; intravenous metoprolol was commenced for rate control. 
His AF rhythm was not converted to sinus rhythm after 24 hours of admission; so, he underwent electrical synchronized cardioversion (150 J) that led to sinus rhythm.

The patient was discharged from hospital after four days in a good condition.

\section{Discussion}

Amiodarone has various side effects including ventricular arrhythmia, QT interval prolongation, abnormality in thyroid function, interstitial lung disease, liver enzymes elevation, and corneal deposits [6-11].

Long term administration of amiodarone is related with blue gray discoloration of the skin which is sensitive to light [12]. However, angioedema is extremely rare as a side effect of amiodarone, and there are few reports about this very uncommon reaction to amiodarone that almost always occurred in chronic use of amiodarone $[13,14]$. To the authors' knowledge, this case is the first report of acutely onset amiodarone-induced angioedema.

As a conclusion, angioedema should be considered as a rare side effect of amiodarone which is used broadly in cardiovascular field.

\section{Conflict of Interests}

The authors declare that there is no conflict of interests regarding the publication of this paper.

\section{References}

[1] G. V. Naccarelli, H. Varker, J. Lin, and K. L. Schulman, "Increasing prevalence of atrial fibrillation and flutter in the United States," American Journal of Cardiology, vol. 104, no. 11, pp. 1534-1539, 2009.

[2] J. Heeringa, D. A. M. van der Kuip, A. Hofman et al., "Prevalence, incidence and lifetime risk of atrial fibrillation: the Rotterdam study," European Heart Journal, vol. 27, no. 8, pp. 949-953, 2006.

[3] D. Roy, M. Talajic, P. Dorian et al., "Amiodarone to prevent recurrence of atrial fibrillation," The New England Journal of Medicine, vol. 342, no. 13, pp. 913-920, 2000.

[4] B. N. Singh, S. N. Singh, D. J. Reda et al., "Amiodarone versus sotalol for atrial fibrillation," The New England Journal of Medicine, vol. 352, no. 18, pp. 1861-1872, 2005.

[5] N. Goldschlager, A. E. Epstein, G. Naccarelli, B. Olshansky, and B. Singh, "Practical guidelines for clinicians who treat patients with amiodarone," Archives of Internal Medicine, vol. 160, no. 12, pp. 1741-1748, 2000.

[6] T. H. Hauser, D. S. Pinto, M. E. Josephson, and P. Zimetbaum, "Safety and feasibility of a clinical pathway for the outpatient initiation of antiarrhythmic medications in patients with atrial fibrillation or atrial flutter," The American Journal of Cardiology, vol. 91, no. 12, pp. 1437-1441, 2003.

[7] E. N. Pearce, A. P. Farwell, and L. E. Braverman, "Thyroiditis," The New England Journal of Medicine, vol. 348, no. 26, pp. 26462655, 2003.

[8] E. N. Pearce, A. P. Farwell, and L. E. Braverman, "Thyroiditis," The New England Journal of Medicine, vol. 348, pp. 2646-2655,
2003, Erratum in: The New England Journal of Medicine, vol. 349, p. 620, 2003.

[9] B. Olshansky, M. Sami, A. Rubin et al., "Use of amiodarone for atrial fibrillation in patients with preexisting pulmonary disease in the AFFIRM study," American Journal of Cardiology, vol. 95, no. 3, pp. 404-405, 2005.

[10] A. J. Sanyal, "AGA technical review on nonalcoholic fatty liver disease," Gastroenterology, vol. 123, no. 5, pp. 1705-1725, 2002.

[11] E. A. Raeder, P. J. Podrid, and B. Lown, "Side effects and complications of amiodarone therapy," The American Heart Journal, vol. 109, no. 5 I, pp. 975-983, 1985.

[12] K. Rappersberger, H. Honigsmann, B. Ortel, A. Tanew, K. Konrad, and K. Wolff, "Photosensitivity and hyperpigmentation in amiodarone-treated patients: incidence, time course, and recovery," Journal of Investigative Dermatology, vol. 93, no. 2, pp. 201-209, 1989.

[13] E. Burches, F. Garcia-Verdegay, M. Ferrer, and A. Pelaez, "Amiodarone-induced angiedema," Allergy, vol. 55, no. 12, pp. 1199-1200, 2000.

[14] K. Lahiri, S. Malakar, and N. Sarma, "Amiodarone-induced angioedema: report of two cases," Indian Journal of Dermatology, Venereology and Leprology, vol. 71, no. 1, pp. 46-47, 2005. 


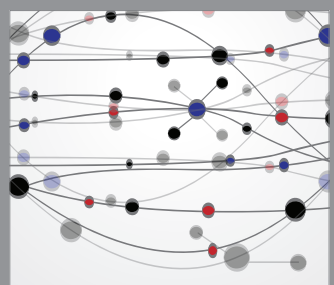

The Scientific World Journal
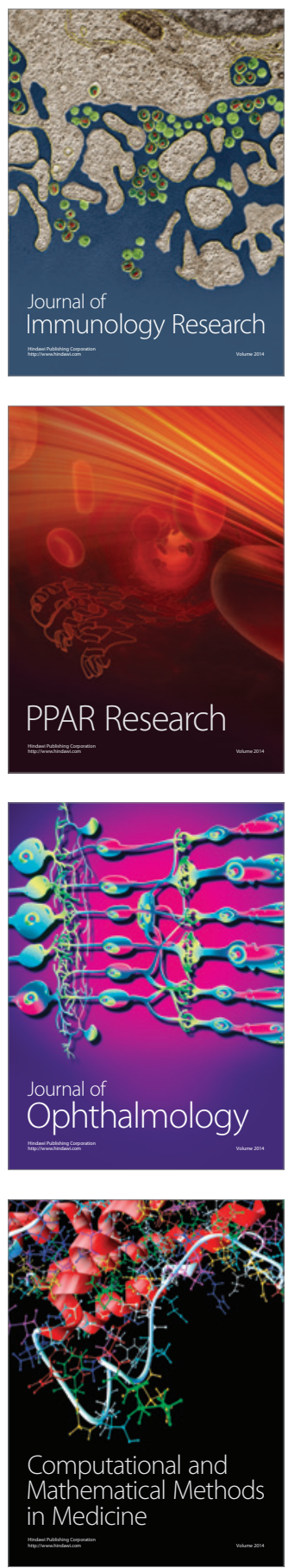



Gastroenterology

Research and Practice
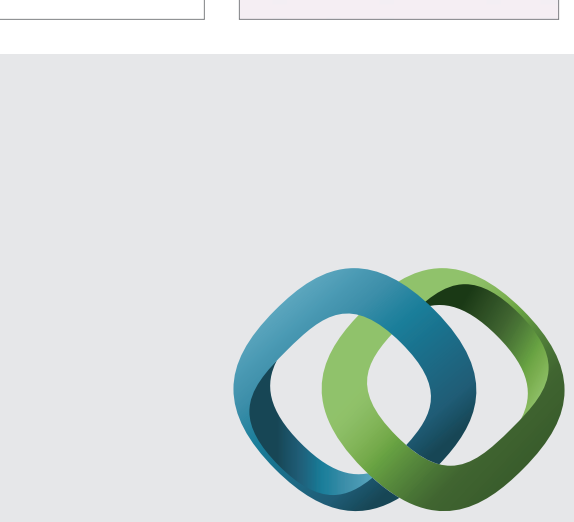

\section{Hindawi}

Submit your manuscripts at

http://www.hindawi.com

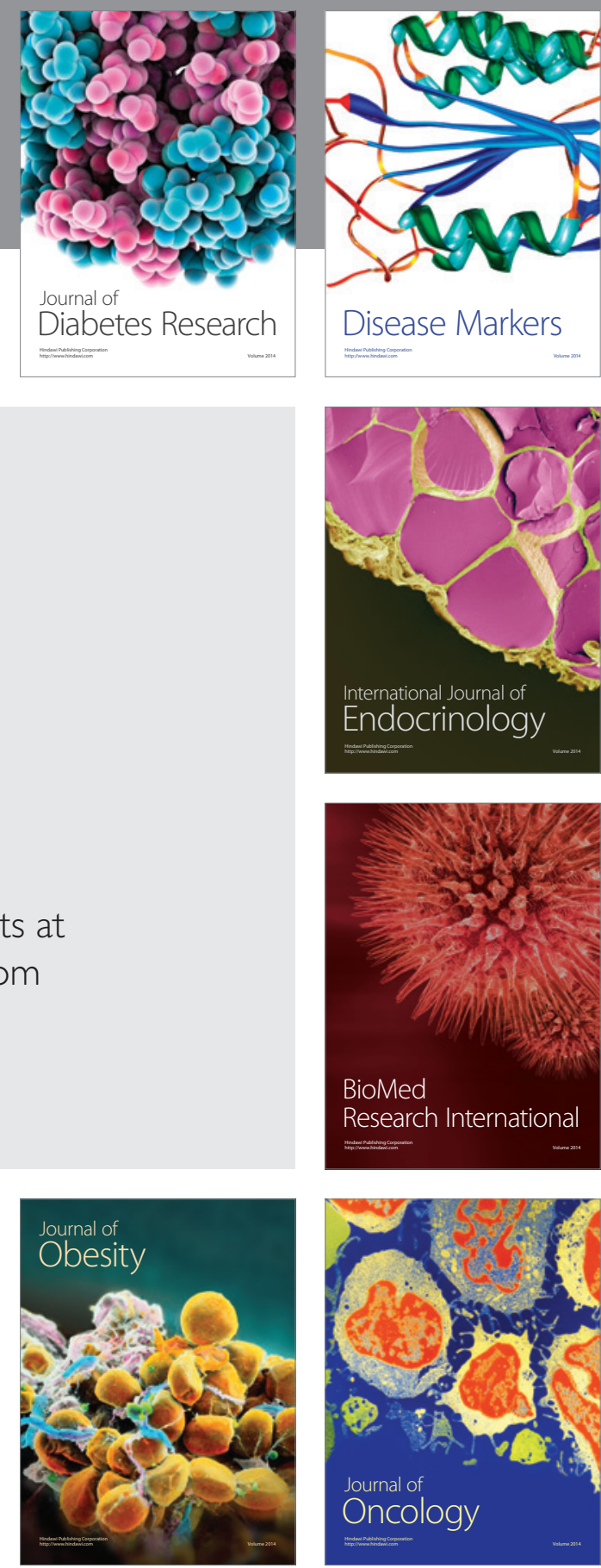

Disease Markers
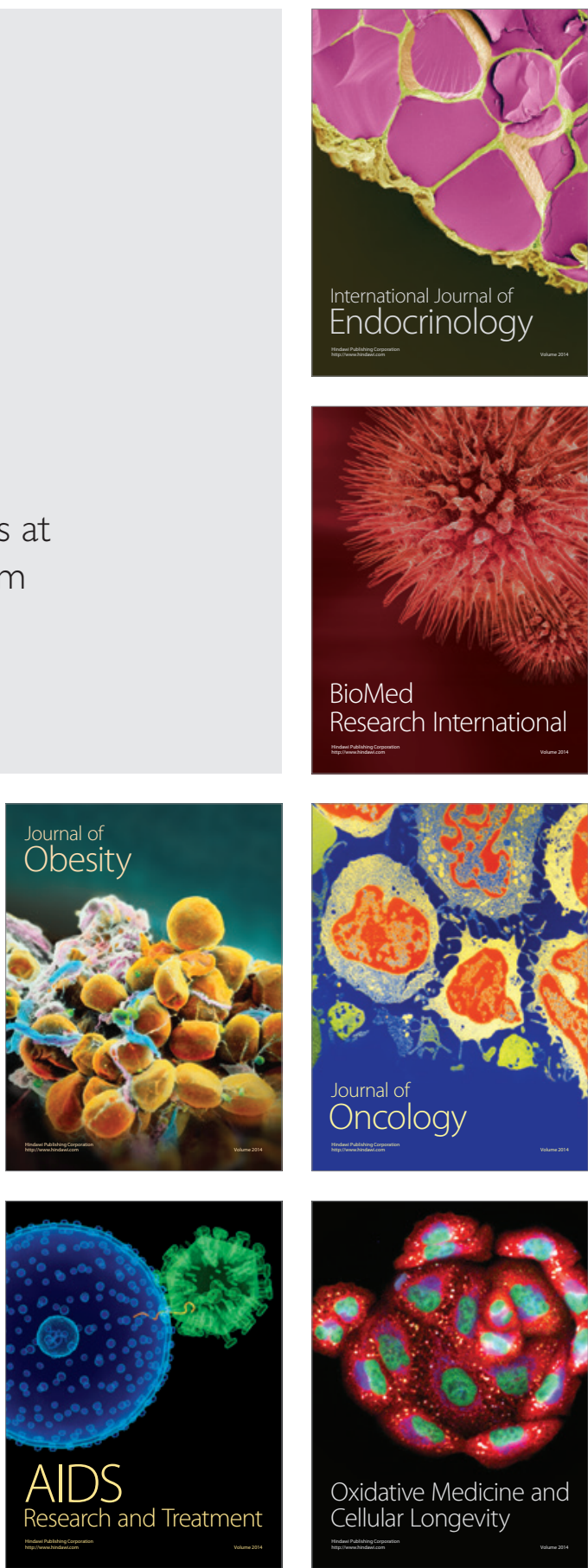